\title{
Age, Sex, and Racial Differences in Neuroimaging Use in Acute Stroke: A Population-Based Study
}

\author{
(D) A. Vagal, (D). Sanelli, (DH. Sucharew, DK.A. Alwell, (D).C. Khoury, (DP. Khatri, DD. Woo, (D) M. Flaherty, (D) B.M. Kissela, \\ (D) Adeoye, (DS. Ferioli, (D)F. De Los Rios La Rosa, (D). Martini, (D). Mackey, and (DD. Kleindorfer
}

\begin{abstract}
BACKGROUND AND PURPOSE: Limited information is available regarding differences in neuroimaging use for acute stroke work-up. Our objective was to assess whether race, sex, or age differences exist in neuroimaging use and whether these differences depend on the care center type in a population-based study.
\end{abstract}

MATERIALS AND METHODS: Patients with stroke (ischemic and hemorrhagic) and transient ischemic attack were identified in a metropolitan, biracial population using the Greater Cincinnati/Northern Kentucky Stroke Study in 2005 and 2010. Multivariable regression was used to determine the odds of advanced imaging use (CT angiography/MR imaging/MR angiography) for race, sex, and age.

RESULTS: In 2005 and 2010, there were 3471 and 3431 stroke/TIA events, respectively. If one adjusted for covariates, the odds of advanced imaging were higher for younger ( 55 years or younger) compared with older patients, blacks compared with whites, and patients presenting to an academic center and those seen by a stroke team or neurologist. The observed association between race and advanced imaging depended on age; in the older age group, blacks had higher odds of advanced imaging compared with whites (odds ratio, 1.34; 95\% $\mathrm{Cl}$, $1.12-1.61 ; P<.01)$, and in the younger group, the association between race and advanced imaging was not statistically significant. Age by race interaction persisted in the academic center subgroup $(P<.01)$, but not in the nonacademic center subgroup $(P=.58)$. No significant association was found between sex and advanced imaging.

CONCLUSIONS: Within a large, biracial stroke/TIA population, there is variation in the use of advanced neuroimaging by age and race, depending on the care center type.

ABBREVIATION: GCNKSS = Greater Cincinnati/Northern Kentucky Stroke Study

S troke is the fifth leading cause of death and a leading cause of disability in the United States. ${ }^{1}$ According to national mortality statistics from the Centers from Disease Control and Preven-

Received September 12, 2016; accepted after revision June 5, 2017.

From the Departments of Radiology (A.V.), Emergency Medicine (O.A.), and Neurology (K.A.A., P.K., D.W., M.F., B.M.K., S.F., F.D.L.R.L.R., S.M., D.K.), University of Cincinnati Medical Center, Cincinnati, Ohio; Department of Radiology (P.S.), Hofstra Northwell School of Medicine, Hempstead, New York; Department of Biostatistics and Epidemiology (H.S., J.C.K.), Cincinnati Children's Hospital Medical Center, Cincinnati, Ohio; Baptist Health Neuroscience Center (F.D.L.R.L.R.), Miami, Florida; University of New Mexico Health Sciences Center and Department of Neurology (F.D.L.R.L.R.), Albuquerque, New Mexico; and Department of Neurology (J.M.), Indiana University School of Medicine, Indianapolis, Indiana.

This work was supported by National Institute of Health grant R01NS30678.

Paper previously presented as oral presentation at: Annual Meeting of the American Society of Neuroradiology and the Foundation of the ASNR Symposium, May 21-26, 2016; Washington, DC.

Please address correspondence to Achala Vagal, MD, MS, Department of Radiology, University of Cincinnati Medical Center, 234 Goodman St, Cincinnati, OH 45267; e-mail: vagala@ucmail.uc.edu

-- Indicates open access to non-subscribers at www.ajnr.org

http://dx.doi.org/10.3174/ajnr.A5340 tion, racial disparities in mortality were largest for stroke, among the leading causes of death. ${ }^{2}$ The National Health and Nutrition Survey Epidemiologic Follow-Up Study ${ }^{3}$ estimated that mortality due to cerebrovascular disease accounted for $28 \%$ of the difference in total mortality rates between blacks and whites. During 2010-2013, stroke mortality among those aged 45 and older varied by age and race. There was a markedly higher stroke death rate in non-Hispanic black individuals than in any of the other raceethnicity groups, and a greater portion of their stroke deaths occurred at younger ages (45-64 years). ${ }^{4}$ Studying trends in stroke incidence and case fatality is critical for the planning, implementation, and evaluation of the public health effort to decrease the burden of stroke in the United States.

Previous studies have shown compelling sex, racial, and socioeconomic disparities in the treatment and outcomes among patients with acute stroke. ${ }^{5-7}$ Generally, racial minorities and women with acute stroke have lower quality hospital care, ${ }^{5,8-13}$ including the use of imaging. These disparities can contribute to inequality in stroke outcomes and are a top research priority of 
the National Institute of Neurologic Disorders and Stroke. The management of stroke begins with the appropriate diagnostic work-up. Imaging is an important component in both evaluation and decision-making in patients presenting with suspected acute stroke. In particular, early vascular imaging, such as CTA/MRA, is now critical for clinical decision-making in patients potentially eligible for endovascular therapy, and urgent brain MR imaging and vascular imaging are recommended in suspected transient ischemic attack. ${ }^{14}$ Although numerous publications have highlighted the disparities in stroke care, very limited data describe demographic differences in neuroimaging use in a population. These observations motivated us to examine data from a large population-based cohort for evidence of systematically different imaging work-up in patients with stroke based on race, sex, or age. If the sources and causes of disparities in stroke care are recognized, these can then inform the setup of programs and initiatives to improve stroke care. This information will also be critical as we transition to value-based health care.

The Greater Cincinnati/Northern Kentucky Stroke Study (GCNKSS) is designed to investigate stroke incidence rates and case fatality in a biracial population (blacks and whites) of a 5 -county region that includes the city of Cincinnati. Our objective was to assess whether race, sex, or age differences exist in neuroimaging use in routine acute stroke practice within this large, metropolitan, population-based cohort and whether these differences depend on care center type.

\section{MATERIALS AND METHODS}

\section{Study Design/Study Population}

This was a retrospective, population-based study of all adults (20 years of age and older) with acute stroke among residents of a 5 -county region of Southwest Ohio and Northern Kentucky during 2005 and 2010. Patients with acute stroke (ischemic and hemorrhagic) and TIA were identified in a population of 1.3 million served by 15 different inpatient hospitals in the Greater Cincinnati/ Northern Kentucky area. The GCNKSS involved ascertainment of all stroke events that occurred in the population in 2005 and 2010.

\section{Methodology and Study Population of the GCNKSS}

The detailed methodology of GCNKSS has been published before. ${ }^{15}$ The study population is defined as all residents of the Greater Cincinnati/Northern Kentucky region, which includes 2 Southern Ohio counties and 3 contiguous Northern Kentucky counties that abut the Ohio River. The study population of the Greater Cincinnati/Northern Kentucky region consists of $<3 \%$ Hispanic and other minorities; all self-identified black or white subjects were included in our analysis. There were 2 methods of screening: retrospective review of discharge diagnoses and prospective monitoring of emergency department visits and admission lists. To qualify as an incidence case, a person must have met the criteria for 1 of the 5 stroke/TIA subcategories, lived at a zip code within the 5-county region at the time of stroke onset, and had the onset of stroke in 2005 (between January 1, 2005, and December 31, 2005) or 2010 (between January 1, 2010, and December 31,2010). Strokes were classified as first-ever or recurrent on the basis of evidence of prior clinical stroke in the medical record. The date and type of each prior stroke or TIA were re- corded, and any neurologic deficit present before the current stroke or TIA was documented. We have current institutional review board approval at all the regional hospitals.

\section{Clinical and Imaging Data Abstraction}

Screening. Screening techniques were identical in both the 2005 and 2010 study periods. Study nurses prospectively screened the medical records of all inpatients with primary or secondary stroke-related International Classification of Diseases, 9th Revision discharge diagnoses from the 15 acute care hospitals in the study region. The International Classification of Diseases, 9th RevisionClinical Modification codes (both primary and secondary discharge diagnoses) for retrieving medical records included 430436. In addition, strokes not found by inpatient screening were ascertained by monitoring all stroke-related visits to hospital emergency departments (with the exception of the Cincinnati Children's Hospital Medical Center). Patient charts and imaging records abstracted by research nurses were reviewed by study physicians. Study physicians reviewed every abstract to verify whether a stroke or TIA had occurred and then assigned a stroke category and mechanism to each event on the basis of all available information, using definitions described previously. ${ }^{16}$

Stroke Case Adjudication. Study nurses and physicians were trained extensively before case review, and detailed instructions guided reviewers on screening, abstraction, and case review. Specifically, study physicians reviewed all data from each case, including clinical scenarios, presenting symptoms, and imaging (CT and/or MR imaging reports, and images if physician-requested). In addition, senior investigators reviewed a select sample of cases from all physician reviewers to ensure accuracy of case ascertainment, and any discrepancies or questionable cases were resolved by senior investigators.

We included all acute ischemic or hemorrhagic stroke or TIA cases ascertained in the hospital setting, including all emergency departments and inpatient services (direct admissions and inhospital events). The cases included in this analysis were restricted to hospitalized patients because the collection of outpatient imaging performed in a nursing home or physician's office setting was not pursued in the study. Socioeconomic status was determined by the percentage below the poverty level within a respondent's US 2000 Census Tract of residence and dichotomized at high poverty $\geq 20 \%$. $^{17}$

\section{Data Analysis}

The proportion of noncontrast CT, CT angiograms, MR imaging, MR angiograms, and carotid sonograms within 2 days of stroke/ TIA symptom onset was computed by sex, age ( 55 or younger or older than 55 years), and race (white or black) demographic groups. We specifically used the 2-day limit to capture all imaging performed for both acute stroke and TIA work-up. In our previous work, ${ }^{18}$ we found a trend toward an increased incidence of ischemic stroke in the young (20-54 years of age) for both black and white patients. We used this same age limit (55 years) to dichotomize the current study group into young versus old.

We used multivariable logistic regression to determine the odds of advanced imaging use for the demographic variables of 
interest (age, sex, and race), adjusting for additional covariates. We defined advanced imaging as additional CT or MR imaging, including CTA head and/or neck, MR imaging brain, and MRA head and/or neck. Covariates included NIHSS score; an indicator for high poverty (percentage below poverty level $\geq 20 \%$ ); emergency department presentation; insurance; type of case (hemorrhagic, ischemic, or TIA); seen by the stroke team or neurologist; type of care center (academic or nonacademic); and study year (2005 or 2010). We defined "academic center" as one with a neurology residency program where neurology is the primary admitting service for patients with stroke. Interaction terms for study year by age, sex, and race and age by race, age by sex, and race by sex were evaluated in the model with a $P<.05$ considered statistically significant. Statistically significant interactions were described by stratification by the effect modifier. Last, we also stratified cases on the basis of type of care center to evaluate whether any observed associations were consistent across the type of care center, with further stratification by any significant effect modifiers.

\section{RESULTS}

In 2005, there were 3471 stroke/TIA events with imaging data available in 3226 patients; and in 2010, there were 3431 stroke/

Table 1: Demographics and clinical characteristics overall and by study year

\begin{tabular}{lccc}
\hline & $\begin{array}{c}\text { All } \\
(\mathbf{N}=6902)\end{array}$ & $\begin{array}{c}2005 \\
(\boldsymbol{n}=3471)\end{array}$ & $\begin{array}{c}2010 \\
(\boldsymbol{n}=3431)\end{array}$ \\
\hline Age (median) (IQR) & $72(59-81)$ & $72(59-81)$ & $71(58-82)$ \\
Race & $1355(20 \%)$ & $659(19 \%)$ & $696(20 \%)$ \\
$\quad$ Black & $5505(80 \%)$ & $2791(80 \%)$ & $2714(79 \%)$ \\
White & $42(1 \%)$ & $21(1 \%)$ & $21(1 \%)$ \\
Other & $3906(57 \%)$ & $1968(57 \%)$ & $1938(56 \%)$ \\
Sex, female & $754(11 \%)$ & $399(12 \%)$ & $355(10 \%)$ \\
Percentage below & & & \\
$\quad$ poverty $\geq 20 \%$ & & & \\
Care center & $1026(15 \%)$ & $440(13 \%)$ & $586(17 \%)$ \\
$\quad$ Academic & $5876(85 \%)$ & $3031(87 \%)$ & $2845(83 \%)$ \\
$\quad$ Nonacademic & $6023(87 \%)$ & $2955(85 \%)$ & $3068(89 \%)$ \\
ED presentation & & & \\
Insurance & $6319(94 \%)$ & $3159(95 \%)$ & $3160(93 \%)$ \\
$\quad$ Any & $415(6 \%)$ & $172(5 \%)$ & $243(7 \%)$ \\
$\quad$ Self-pay & $3(1-7)$ & $3(1-7)$ & $2(1-6)$ \\
NIHSS (median) (IQR) & & & \\
Case type & $821(12 \%)$ & $427(12 \%)$ & $394(11 \%)$ \\
$\quad$ Hemorrhagic & $4412(64 \%)$ & $2147(62 \%)$ & $2265(66 \%)$ \\
Ischemic & $1669(24 \%)$ & $897(26 \%)$ & $772(22 \%)$ \\
$\quad$ TIA & $4287(62 \%)$ & $2006(58 \%)$ & $2281(66 \%)$ \\
Seen by stroke team & & \\
$\quad$ or neurologist & & & \\
\hline Nete- & &
\end{tabular}

Note:- IQR indicates interquartile range; ED, emergency department.

${ }^{a}$ Data are No. (\%) unless otherwise indicated.
TIA events with imaging data available in 3213 patients. Because demographic differences in imaging use did not differ significantly between the calendar years 2005 and 2010, data for the 2 years were combined. The median age for the combined group was 72 years, $20 \%$ were black, $57 \%$ were women, and the median NIHSS score was 3 (Table 1). A higher proportion of men underwent MR imaging (55\% versus 51\%, $P<.01)$ and MRA $(36 \%$ versus $31 \%, P<.01$ ) compared with women, with no sex differences in the use of NCCT, carotid sonography, or CTA. A higher proportion of blacks underwent NCCT (96\% versus 92\%), MR imaging (59\% versus 51\%), and MRA (41\% versus 31\%) compared with whites $(P<.01)$, with no racial difference in CTA. Advanced imaging use (MR imaging, CTA, MRA) was higher in younger (55 years or younger) compared with older patients (older than 55 years) (68\% versus 52\%, $P<.01$ ), whereas older patients underwent a higher proportion of carotid sonography (43\% versus $36 \%, P<.01)$ (Table 2 ).

\section{Multivariable Analysis}

After we adjusted for covariates, younger age (55 years or younger) was associated with higher odds of advanced imaging compared with older age (older than 55) (adjusted odds ratio, 1.90; 95\% CI, 1.63-2.22; $P<.01$ ). Compared with white patients, black patients had significantly higher odds of additional advanced imaging (OR, 1.27; 95\% CI, 1.08-1.49; $P<.01)$. The odds of advanced imaging were also higher if patients presented to an academic center or were seen by a stroke team or neurologist. No statistically significant association was found between sex and advanced imaging (Table 3). A higher NIHSS score was associated with decreased advanced imaging (OR, 0.93; 95\% CI, 0.92-0.94; $P<.01)$.

We found a significant age-by-race interaction so that the association between race and advanced imaging was dependent on age. After we adjusted for covariates, in the older age group, black race was associated with higher odds of advanced imaging compared with white race (OR, 1.34; 95\% CI, 1.12-1.61; $P<.01)$. However, in the younger age group, the association between race and advanced imaging was not statistically significant (Table 3). No statistically significant interactions were found between study year and age, sex, and race, between age and sex, and between age and race.

In subgroup analyses by type of center, the age-by-race interaction persisted in the academic center subgroup $(P<.01)$, but not in the nonacademic center subgroup $(P=.58)$. In the academic center, in the older age group, black race was associated with higher odds of advanced imaging compared with white race

Table 2: Unadjusted neuroimaging use for stroke/TIA work-up by sex, age, and race for combined study periods of 2005 and $2010^{\mathrm{a}}$

\begin{tabular}{|c|c|c|c|c|c|c|c|c|c|}
\hline & \multicolumn{3}{|c|}{ Sex } & \multicolumn{3}{|c|}{ Age (yr) } & \multicolumn{3}{|c|}{ Race } \\
\hline & $\begin{array}{c}\text { Men } \\
(n=2996)\end{array}$ & $\begin{array}{c}\text { Women } \\
(n=3906)\end{array}$ & $\begin{array}{c}P \\
\text { Value }\end{array}$ & $\begin{array}{c}55 \text { or Younger } \\
(n=1343)\end{array}$ & $\begin{array}{c}\text { Older Than } 55 \\
(n=5559)\end{array}$ & $\begin{array}{c}P \\
\text { Value }\end{array}$ & $\begin{array}{c}\text { Black } \\
(n=1355)\end{array}$ & $\begin{array}{c}\text { White } \\
(n=5505)\end{array}$ & $\begin{array}{c}P \\
\text { Value }\end{array}$ \\
\hline $\mathrm{NCCT}$ & $2778(93 \%)$ & 3649 (93\%) & .26 & 1265 (94\%) & $5162(93 \%)$ & .08 & $1296(96 \%)$ & $5091(92 \%)$ & $<.01$ \\
\hline MRI & $1633(55 \%)$ & 1983 (51\%) & $<.01$ & $851(63 \%)$ & 2765 (50\%) & $<.01$ & 801 (59\%) & 2788 (51\%) & $<.01$ \\
\hline CTA & $163(5 \%)$ & $184(5 \%)$ & .17 & $130(10 \%)$ & $217(4 \%)$ & $<.01$ & $81(6 \%)$ & $263(5 \%)$ & .07 \\
\hline MRA & $1075(36 \%)$ & $1206(31 \%)$ & $<.01$ & $569(42 \%)$ & $1712(31 \%)$ & $<.01$ & $561(41 \%)$ & $1703(31 \%)$ & $<.01$ \\
\hline Any advanced imaging & $1718(57 \%)$ & $2104(54 \%)$ & $<.01$ & $916(68 \%)$ & 2906 (52\%) & $<.01$ & $847(63 \%)$ & 2948 (54\%) & $<.01$ \\
\hline Carotid sonography & $1246(42 \%)$ & 1614 (41\%) & .82 & $482(36 \%)$ & $2378(43 \%)$ & $<.01$ & 417 (31\%) & 2425 (44\%) & $<.01$ \\
\hline
\end{tabular}

${ }^{\mathrm{a}}$ Data are No. (\%) unless otherwise indicated. 
Table 3: Multivariable model for advanced imaging (CTA/MRI/MRA) for stroke/TIA work-up in the overall group stratified by age groups

\begin{tabular}{|c|c|c|c|c|c|c|}
\hline & \multicolumn{2}{|c|}{ Overall } & \multicolumn{2}{|c|}{55 yr or Younger } & \multicolumn{2}{|c|}{ Older Than 55 yr } \\
\hline & OR $(95 \% \mathrm{Cl})$ & $P$ Value & OR $(95 \% \mathrm{Cl})$ & $P$ Value & OR $(95 \% \mathrm{Cl})$ & $P$ Value \\
\hline Age 55 yr or younger & $1.90(1.63-2.22)$ & $<.01$ & - & - & - & - \\
\hline Race, black (reference white) ${ }^{a}$ & $1.27(1.08-1.49)$ & $<.01$ & $1.02(0.73-1.41)$ & .92 & $1.34(1.12-1.61)$ & $<.01$ \\
\hline Sex, male & $1.06(0.95-1.18)$ & .32 & $1.06(0.81-1.39)$ & 69 & $1.06(0.94-1.20)$ & .31 \\
\hline Academic & 1.43 (1.20-1.71) & $<.01$ & $1.21(0.85-1.72)$ & .29 & $1.51(1.22-1.85)$ & $<.01$ \\
\hline High poverty & $0.85(0.69-1.03)$ & .10 & $0.71(0.49-1.04)$ & .08 & $0.91(0.73-1.15)$ & .44 \\
\hline ED presentation & $1.95(1.65-2.29)$ & $<.01$ & $2.74(1.81-4.14)$ & .01 & $1.84(1.54-2.19)$ & $<.01$ \\
\hline Insurance (any, reference self-pay) & $0.91(0.70-1.18)$ & .47 & $0.90(0.63-1.28)$ & .56 & $0.94(0.64-1.39)$ & .76 \\
\hline NIHSS score & $0.93(0.92-0.94)$ & $<.01$ & $0.93(0.92-0.95)$ & $<.01$ & $0.93(0.92-0.94)$ & $<.01$ \\
\hline \multicolumn{7}{|l|}{ Event type (reference TIA) } \\
\hline $\mathrm{ICH} / \mathrm{SAH}$ & $1.22(0.99-1.50)$ & .07 & $1.98(1.26-3.12)$ & $<.01$ & $1.04(0.82-1.33)$ & .72 \\
\hline Infarct & $2.51(2.19-2.88)$ & $<.01$ & $2.46(1.78-3.41)$ & $<.01$ & $2.50(2.16-2.91)$ & $<.01$ \\
\hline Seen by stroke team or neurologist & $2.33(2.07-2.63)$ & $<.01$ & $3.25(2.38-4.43)$ & $<.01$ & $2.22(1.95-2.53)$ & $<.01$ \\
\hline Study year 2010 (reference 2005) & $1.66(1.48-1.85)$ & $<.01$ & $1.77(1.35-2.33)$ & $<.01$ & $1.64(1.46-1.85)$ & $<.01$ \\
\hline
\end{tabular}

Note:-ED indicates emergency department; ICH, intracranial hemorrhage.

${ }^{a}$ Race by age group interaction $(P=.04)$

Table 4: Multivariable model for advanced imaging (CTA/MRI/MRA) for stroke/TIA work-up stratified by care center type and age groups

\begin{tabular}{|c|c|c|c|c|c|c|c|c|}
\hline & \multicolumn{4}{|c|}{ Academic Center $(n=1026)^{a}$} & \multicolumn{4}{|c|}{ Nonacademic Centers $(n=5876)^{b}$} \\
\hline & \multicolumn{2}{|c|}{55 yr or Younger } & \multicolumn{2}{|c|}{ Older Than 55 yr } & \multicolumn{2}{|c|}{55 yr or Younger } & \multicolumn{2}{|c|}{ Older Than 55 yr } \\
\hline & OR $(95 \% \mathrm{Cl})$ & $\begin{array}{c}P \\
\text { Value }\end{array}$ & OR $(95 \% \mathrm{Cl})$ & $\begin{array}{c}P \\
\text { Value }\end{array}$ & OR $(95 \% \mathrm{Cl})$ & $\begin{array}{c}P \\
\text { Value }\end{array}$ & OR $(95 \% \mathrm{Cl})$ & $\begin{array}{c}P \\
\text { Value }\end{array}$ \\
\hline Race, black (reference white) & $0.56(0.30-1.04)$ & .07 & $1.80(1.19-2.72)$ & $<.01$ & $1.25(0.82-1.89)$ & .29 & $1.27(1.04-1.55)$ & .02 \\
\hline Sex, male & $1.00(0.58-1.72)$ & .99 & $1.25(0.88-1.78)$ & .22 & $1.12(0.82-1.54)$ & .48 & $1.05(0.92-1.20)$ & .46 \\
\hline High poverty & $0.98(0.51-1.85)$ & .94 & $0.74(0.47-1.17)$ & .20 & $0.64(0.40-1.03)$ & .07 & $0.98(0.75-1.28)$ & .89 \\
\hline ED presentation & $2.09(0.89-4.91)$ & .09 & $1.79(1.03-3.12)$ & .04 & $3.19(1.94-5.24)$ & $<.01$ & $1.83(1.52-2.20)$ & $<.01$ \\
\hline Insurance (any, reference self-pay) & $0.77(0.45-1.33)$ & .35 & $0.84(0.45-1.56)$ & .58 & $0.92(0.57-1.47)$ & .73 & $0.99(0.61-1.60)$ & .95 \\
\hline NIHSS & $0.94(0.92-0.97)$ & $<.01$ & $0.94(0.92-0.95)$ & $<.01$ & $0.91(0.89-0.94)$ & $<.01$ & $0.93(0.92-0.94)$ & $<.01$ \\
\hline \multicolumn{9}{|l|}{ Event type (reference TIA) } \\
\hline $\mathrm{ICH} / \mathrm{SAH}$ & $0.99(0.34-2.85)$ & .98 & $1.54(0.80-2.96)$ & .20 & $2.46(1.40-4.34)$ & $<.01$ & $0.87(0.65-1.17)$ & .37 \\
\hline Infarct & $2.12(0.93-4.88)$ & .08 & $1.85(1.10-3.11)$ & .02 & $2.44(1.68-3.55)$ & $<.01$ & $2.58(2.20-3.01)$ & $<.01$ \\
\hline Seen by stroke team or neurologist & $2.39(1.02-5.56)$ & .04 & $3.02(1.75-5.20)$ & $<.01$ & $3.80(2.68-5.38)$ & $<.01$ & $2.21(1.93-2.53)$ & $<.01$ \\
\hline Study year 2010 (reference 2005) & $3.84(2.23-6.62)$ & $<.01$ & $1.88(1.31-2.68)$ & $<.01$ & $1.38(1.00-1.90)$ & .05 & $1.61(1.42-1.83)$ & $<.01$ \\
\hline
\end{tabular}

Note:-ED indicates emergency department; ICH, intracranial hemorrhage.

${ }^{a}$ In the academic care center subgroup: race by age group interaction $(P<.01)$.

${ }^{b}$ In the nonacademic care center subgroup: race by age group interaction $(P=.58)$.

(OR, 1.80; 1.12-1.61; $P<.01)$. However, in the younger age group, the association between black race and advanced imaging was in the opposite direction and not statistically significant (Table 4). In the nonacademic center, black race was associated with higher odds of advanced imaging in both age groups (unstratified OR, 1.28; 95\% CI, 1.07-1.53; $P<.01)$.

\section{DISCUSSION}

The principal finding of our study is that younger patients (55 year or younger) and black patients were more likely to undergo advanced imaging for acute stroke/TIA work-up. Although men underwent a significantly higher proportion of MR imaging/ MRA in unadjusted analyses, this association was not present after adjusting for covariates. Additionally, we did not find a significant difference in the use of advanced imaging by insurance or socioeconomic status.

Prior studies have shown demographic differences in the use of neuroimaging for acute stroke. ${ }^{15,19}$ Large variation was reported among English public hospitals, where younger patients, men, and patients of higher socioeconomic status were more likely to undergo brain imaging (NCCT or MR imaging). ${ }^{11} \mathrm{~A}$ study using the Canadian Stroke Registry found that very elderly patients were less likely to undergo carotid imaging compared with younger patients with acute ischemic stroke, though there was no association between age and the quality of stroke care. ${ }^{17}$ In our analysis, a higher proportion of the older patients underwent carotid sonography rather than CTA or MRA, compared with younger patients. A possible explanation is that older patients are less suitable candidates for carotid endarterectomy or carotid artery stent placement due to other comorbidities, including dementia; therefore, advanced vascular imaging is less likely to be performed. Additionally, younger patients may have more stroke mimics, leading to increased advanced imaging.

The strength of our study is that it is the largest populationbased dataset capturing detailed clinical information regarding stroke care in the United States, and it is one of the few studies with a substantial number of black patients. In addition, our dataset represents a large, metropolitan population representative of the United States population with respect to median age, median income, black race, female sex, and rate below the poverty level. ${ }^{16,20}$

There is a distinct advantage in using a population-based source of information regarding imaging use patterns. Popula- 
tion-based epidemiologic studies of stroke fall into 2 broad classes: 1) surveillance studies, and 2) cohort studies; both are needed to fully understand stroke incidence and disparities. Just as cohort studies are critical to the understanding of the causes of stroke, surveillance studies are critical to determining the distribution of stroke; and both contribute to knowledge regarding important public health trends in stroke. Similarly, administrative data provide complementary data to population-based studies by providing access to large numbers of cases with lower costs. However, administrative data lack the ability to answer clinical questions, have incomplete ascertainment, and have limited access to special populations. Registries, such as Get With the Guidelines, ${ }^{21}$ provide more clinical information than purely administrative data, though they are still limited compared with population-based studies. Providing data in these registries by hospitals demonstrates a willingness to participate in stroke quality-improvement projects, indicating a bias at the hospital level.

Most surprising, in contrast to concerns that blacks may receive less diagnostic work-up, we found that overall, blacks received more advanced imaging than whites. A possible explanation is that in our population, the only large, academic hospital in the region admits a greater proportion of black patients. Furthermore, the racial difference depended on age and type of care center, with potential differential access to stroke expertise. A retrospective analysis of US Department of Veterans Affairs Hospital systems also suggested sites of care as a factor for disparities by demonstrating that white patients at nonminority-serving hospitals had a significantly higher probability of undergoing carotid imaging than either black or white patients at minority-serving hospitals. ${ }^{22}$ In addition, there may be clinical differences between strokes in blacks and whites in our study, including variations in vascular risk factors prompting advanced imaging work-up. We also found that the odds of advanced imaging were higher if patients were seen by a stroke team or neurologist, suggesting that physician factors can have a substantial effect on imaging use. This finding has also been demonstrated in a large retrospective cohort study examining factors affecting the use of outpatient imaging, where specialists ordered $43.6 \%$ compared with $27.5 \%$ ordered by primary care physicians. ${ }^{23}$

Disparity in health care is being increasingly recognized; hence, an overarching goal of the Healthy People 2020 initiative is "to achieve health equity, eliminate disparities, and improve the health of all groups" in the United States. ${ }^{24}$ A recent study demonstrated a significant gap between metropolitan and nonmetropolitan area hospitals, especially with the rate of recombinant tissue plasminogen activator administration and provision of stroke education. ${ }^{25}$ Even more alarming is that this rural-urban geographic disparity gap in rtPA use is increasing. ${ }^{26}$ Several deficiencies contribute to the disparity in stroke care, including widespread geographic variation and access issues. Furthermore, the prehospital recognition of stroke is lower among minority patients compared with non-Hispanic whites and, similarly, lower for female compared with male patients, ${ }^{27}$ highlighting the importance of identifying all links in the chain of stroke care. Lack of awareness, socioeconomic factors, cultural impediments, and potential existence of bias are additional barriers in the delivery of care. $^{5}$
Change in the incidence and outcome of a disease and the reduction of clearly identified disparities in these rates and outcomes are the ultimate test of how well science has translated new discoveries into benefits for the population. Because stroke is the most frequent neurologic cause of death and a leading cause of major disability, it should be a primary focus for neurologic surveillance studies. Understanding use of standard of care (NCCT) versus advanced imaging (MR imaging/CTA/MRA) is important because additional diagnostic imaging, including vascular imaging, can help guide treatment decisions and elucidate etiology and recurrence risk in patients with stroke and TIA. The understanding of the differential use of imaging in various centers, different age groups, and the "at-risk" population is crucial to designing future interventions to reduce stroke risk and quantify the need for standardization of care.

There are a few important limitations to our study, including the retrospective nature. There is a potential for bias of incomplete case ascertainment, though our method of identification of hospitalized strokes is well-defined and remained consistent across the study periods. Despite the surveillance methods in place, it is possible that some cases of stroke and TIA were missed. Although imaging may have an effect on the detection and diagnosis of stroke, the case definition for stroke used in this analysis for both study periods was based strictly on clinical criteria, supported by imaging findings. Another limitation is that the neuroimaging use rates are from older 2005 and 2010 cohorts. We plan to study the imaging use in the 2015 GCNKSS cohort (data collection for the same is underway). Our study also does not have the ability to track how the use of imaging affected clinical decision-making and/or outcomes in the stroke population; however, this area is an important focus for future research.

\section{CONCLUSIONS}

Age- and race-related differences exist in the use of neuroimaging for patients with stroke/TIA, which depends on care center type. Clearly, much work is still needed to understand these disparities. Deconstructing the differences in utilization data must continue because this can provide an important basis for lines of inquiry into socioeconomic and access-to-stroke-care issues. These data are critical for focusing and monitoring the success of the public health effort in decreasing disability and mortality due to stroke.

Disclosures: Achala Vagal—UNRELATED: Grant: CTSA KL2 grant, TR001426-01*. Heidi Sucharew-RELATED: Grant: R01NS30678*; UNRELATED: Employment: Cincinnati Children's Hospital Medical Center*. Kathleen A. Alwell—RELATED: Grant: National Institutes of Health/National Institute of Neurological Disorders and Stroke, Comments: work on the National Institutes of Health grant NS30678*. Jane C. KhouryRELATED: Grant: National Institutes of Health/National Institute of Neurological Disorders and Stroke. Pooja Khatri—RELATED: Grant: National Institutes of Health/ National Institute of Neurological Disorders and Stroke*; UNRELATED: Consultancy: St. Jude's, Grand Rounds Experts, Comments: medicolegal consultations; Royalties: UpToDate; Travel/Accommodations/Meeting Expenses Unrelated to Activities Listed: Neuravi Clot Summit; Other: Genentech pays my department for my PRISMS Principal Investigator effort; Biogen pays me for Data and Safety Monitoring Board member effort*. Daniel Woo-UNRELATED: National Institute of Neurological Disorders and Stroke, Comments: NS036695, NS069763*. Matthew Flaherty-RELATED: Grant: National Institutes of Health; Support for Travel to Meetings for the Study or Other Purposes: National Institutes of Health. Brett M. Kissela-UNRELATED: Grant: National Institutes of Health, Comments: multiple grants, including the National Institutes of Health grant from which this work was produced, NS030678; others include NS041588 and RR026314*; Support for Travel to Meetings for the Study or Other Purposes: Janssen Pharmaceutica; Comments: I was paid to attend a meeting 
for the end point adjudication committee (see next); Fees for Participation in Review Activities such as Data Monitoring Boards, Statistical Analysis, Endpoint Committees, and the Like: AbbVie and Janssen Pharmaceutica, Comments: end point adjudication committees for clinical trials sponsored by these 2 entities. Opeolu Adeoye-RELATED: Grant: National Institutes of Health/National Institute of Neurological Disorders and Stroke, Comments: research grant support; Support for Travel to Meetings for the Study or Other Purposes: National Institutes of Health/ National Institute of Neurological Disorders and Stroke, Comments: research grant support; UNRELATED: Grants/Grants Pending: CereDx, Comments: research grant for stroke plasma biomarker diagnosis; Patents (Planned, Pending or Issued): PCT/ US2011/068095, Comments: patent for noninvasive neurologic monitoring device for intracranial hemorrhage; Other: Sense Diagnostics, Comments: cofounder of the company formed to develop the device referenced in the patent above. Simona Ferioli-RELATED: National Institutes of Health, Comments: GCNKSS*. Felipe De Los Rios La Rosa—RELATED: Grant: National Institutes of Health*. Jason MackeyRELATED: Grant: National Institutes of Health/National Institute of Neurological Disorders and Stroke, R01 NS030678*; UNRELATED: Grants/Grants Pending: IUH-VFR-365, IUH/IUSM Strategic Research Initiative CTSI PDT, National Institutes of Health LRP recipient Indiana University CTSI KL2 award*. Dawn KleindorferRELATED: Grant: National Institutes of Health, Comments: R01 grant*. *Money paid to the institution.

\section{REFERENCES}

1. Mozaffarian D, Benjamin EJ, Go AS, et al; Writing Group Members, American Heart Association Statistics Committee, Stroke Statistics Subcommittee. Executive summary: Heart Disease and Stroke Statistics-2016 Update: a report from the American Heart Association. Circulation 2016;133:447-54 CrossRef Medline

2. Centers for Disease Control and Prevention (CDC). Disparities in deaths from stroke among persons aged $<75$ years: United States, 2002. MMWR Morb Mortal Wkly Rep 2005;54:477-81 Medline

3. Cox CS, Mussolino ME, Rothwell ST, et al. Plan and operation of the NHANES I Epidemiologic Followup Study, 1992. Vital Health Stat 1 1997;1-231 Medline

4. Ingram DD, Montresor-Lopez JA. Differences in stroke mortality among adults aged 45 and over: United States, 2010-2013. NCHS Data Brief 2015:1-8 Medline

5. Cruz-Flores S, Rabinstein A, Biller J, et al American Heart Association Stroke Council, Council on Cardiovascular Nursing, Council on Epidemiology and Prevention, Council on Quality of Care and Outcomes Research. Racial-ethnic disparities in stroke care: the American experience-a statement for healthcare professionals from the American Heart Association/American Stroke Association. Stroke 2011;42:2091-116 CrossRef Medline

6. Boehme AK, Siegler JE, Mullen MT, et al. Racial and gender differences in stroke severity, outcomes, and treatment in patients with acute ischemic stroke. J Stroke Cerebrovasc Dis 2014;23:e255-61 CrossRef Medline

7. Nasr DM, Brinjikji W, Cloft HJ, et al. Racial and ethnic disparities in the use of intravenous recombinant tissue plasminogen activator and outcomes for acute ischemic stroke. J Stroke Cerebrovasc Dis 2013;22:154-60 CrossRef Medline

8. Mozaffarian D, Benjamin EJ, Go AS, et al; American Heart Association Statistics Committee and Stroke Statistics Subcommittee. Heart disease and stroke statistics-2015 update: a report from the American Heart Association. Circulation 2015;131:e29-322 CrossRef Medline

9. Di Carlo A, Lamassa M, Baldereschi M, et al; European BIOMED Study of Stroke Care Group. Sex differences in the clinical presentation, resource use, and 3-month outcome of acute stroke in Europe: data from a multicenter multinational hospital-based registry. Stroke 2003;34:1114-19 CrossRef Medline

10. Reeves MJ, Fonarow GC, Zhao X, et al; Get With The GuidelinesStroke Steering Committee \& Investigators. Quality of care in women with ischemic stroke in the GWTG program. Stroke 2009;40: 1127-33 CrossRef Medline

11. Lazzarino AI, Palmer W, Bottle A, et al. Inequalities in stroke patients' management in English public hospitals: a survey on 200,000 patients. PLoS One 2011;6:e17219 CrossRef Medline

12. Rose KM, Rosamond WD, Huston SL, et al. Predictors of time from hospital arrival to initial brain-imaging among suspected stroke patients: the North Carolina Collaborative Stroke Registry. Stroke 2008;39:3262-67 CrossRef Medline

13. Jacobs BS, Birbeck G, Mullard AJ, et al. Quality of hospital care in African American and white patients with ischemic stroke and TIA. Neurology 2006;66:809-14 CrossRef Medline

14. Powers WJ, Derdeyn CP, Biller J, et al American Heart Association Stroke Council. 2015 American Heart Association/American Stroke Association Focused Update of the 2013 Guidelines for the Early Management of Patients with Acute Ischemic Stroke Regarding Endovascular Treatment: A Guideline for Healthcare Professionals from the American Heart Association/American Stroke Association. Stroke 2015;46:3020 -35 CrossRef Medline

15. Brinjikji W, El-Sayed AM, Rabinstein AA, et al. Disparities in imaging utilization for acute ischemic stroke based on patient insurance status. AJR Am J Roentgenol 2014;203:372-76 CrossRef Medline

16. Broderick J, Brott T, Kothari R, et al. The Greater Cincinnati/Northern Kentucky Stroke Study: preliminary first-ever and total incidence rates of stroke among blacks. Stroke 1998;29:415-21 CrossRef Medline

17. Saposnik G, Black SE, Hakim A, et al; Investigators of the Registry of the Canadian Stroke Network (RCSN), Stroke Outcomes Research Canada (SORCan) Working Group. Age disparities in stroke quality of care and delivery of health services. Stroke 2009;40:3328-35 CrossRef Medline

18. Kissela BM, Khoury JC, Alwell K, et al. Age at stroke: temporal trends in stroke incidence in a large, biracial population. Neurology 2012; 79:1781-87 CrossRef Medline

19. Martin KD, Naert L, Goldstein LB, et al. Comparing the use of diagnostic imaging and receipt of carotid endarterectomy in elderly black and white stroke patients. J Stroke Cerebrovasc Dis 2012;21: 600-06 CrossRef Medline

20. Kleindorfer DO, Lindsell C, Broderick J, et al. Impact of socioeconomic status on stroke incidence: a population-based study. Ann Neurol 2006;60:480-84 CrossRef Medline

21. Schwamm LH, Fonarow GC, Reeves MJ, et al. Get With the Guidelines-Stroke is associated with sustained improvement in care for patients hospitalized with acute stroke or transient ischemic attack. Circulation 2009;119:107-15 CrossRef Medline

22. Cheng EM, Keyhani S, Ofner S, et al. Lower use of carotid artery imaging at minority-serving hospitals. Neurology 2012;79:138-44 CrossRef Medline

23. Sistrom C, McKay NL, Weilburg JB, et al. Determinants of diagnostic imaging use in primary care. Am J Manag Care 2012;18:e135-44 Medline

24. Healthy People 2020 [Internet]. Washington, DC: US Department of Health and Human Services, Office of Disease Prevention and Health Promotion. https://www.healthypeople.gov/2020/About-HealthyPeople. Accessed June 2, 2017

25. Seabury S, Bognar K, Xu Y, et al. Regional disparities in the quality of stroke care. Am J Emerg Med 2017 Mar 19. [Epub ahead of print] CrossRef Medline

26. Gonzales S, Mullen MT, Skolarus L, et al. Progressive rural-urban disparity in acute stroke care. Neurology 2017;88:441-48 CrossRef Medline

27. Govindarajan P, Friedman BT, Delgadillo JQ, et al. Race and sex disparities in prehospital recognition of acute stroke. Acad Emerg Med 2015;22:264-72 CrossRef Medline 